\title{
Clinical management of common cold in the perspective of primary care
}

\author{
Hiroshi Bando* \\ Tokushima University, Medical Research, Tokushima, Japan
}

Human has several systems of organs, such as respiratory, cardiovascular, gastrointestinal, renal, endocrine and so on. Among them, respiratory system seems to be most basal and crucial because of direct threat and influence for the life from newborn to the aged.

When looking back the history of medical practice, medicine has evolved from general practice in ancient times to specialized subspecialty in recent years. Millis report was presented in 1960' for the increased depersonalization of medicine and fragmentation of care [1]. After that, primary care medicine developed in the United States associated with the approved department of Family Medicine [2].

Primary care medicine has been practiced for long by some specialty of physicians. They are family doctors, pediatricians and internists majoring in respiratory, cardiovascular, gastrointestinal, renal diseases and so on. As to PC medicine, diagnosis, treatment, and management of common diseases are more important than rare diseases.

As a matter of fact, one of the most common health problems in daily practice would be cold symptom and cough. From a standard clinical study, new onset of the chest symptom was investigated for a month associated with the evaluation of clinical, socioeconomic and demographic characteristics [3]. In the prospective observational cohort study of about 3477 participants, cough was observed as the most frequent problem with $20.1 \%$. On contrast, other four symptoms were rare in less than $1 \%$ as follows: $0.7 \%$ for chest pain, $0.5 \%$ for dyspnea, $0.4 \%$ for palpitation, and $0.3 \%$ for wheezing. For the symptom of cough, some factors were more associated with unemployment situation, younger age and unsatisfactory physical quality of life [3].

The most frequent chest symptom in the individual was chest symptoms [3]. It is consistent with the previous study that cough has high incidence in general people [4].

In Japan, chest pain, dyspnea, palpitation, and wheezing are relatively uncommon as new onset symptoms [3]. On contrast, chest pain has been rather common symptom in general people associated including cardiac and non-cardiac origins in western countries $[5,6]$

Cough was found more commonly in young generation than elderly [3]. On the other hand, chest pain was more common in the elderly than the young. Previous studies showed that the incidence of cough is elevated in younger children and decreases with age, that it increases higher in the elderly due to chronic obstructive pulmonary disease (COPD) $[7,8]$.

Furthermore, atopic, asthmatic diathesis and variant asthma have considered in rather younger generation because they have often show cough [9]. In contrast, elevated prevalence of chest pain in the elderly people would be from the increased possibility of coronary artery disease.
Primary care medicine includes bio-psycho-social aspects to investigate. Respiratory problems including cough or chest pain showed increased prevalence in the case of low-income, lower education background, smoking and indoor and outdoor pollution in the community environment $[10,11]$.

In the field of primary care, a variety of matters are evaluated from bio-psycho-social points of view. Similarly, common cold has been influenced by psychosomatic situation. In 1938, Saul described that common cold and common sore throat are rather vague conditions with similar symptomatology, and that an infectious agent, a filterable virus and certain emotional disturbance may be involved with the etiology [12]. Incidental rates of respiratory infection and clinical colds are increased in a dose-response manner with the increased degree of psychological stress [13]. Thus, psychosomatic situation seems to be important. Prevalence of self-perceived respiratory symptoms (SRS) was studied in 4544 participants, in which $26 \%$ and $36 \%$ with no diagnosed psychiatric disorder or respiratory disease showed SRS despite a normal spirometry data [14]. It suggested the role of psychological factors for respiratory symptoms and the associated medical burden.

Common cold has been the most frequent disease worldwide and its self-care is important [15]. There was a US study with 3333 patients, in which $85 \%$ had at least one common cold per year lasting 3-7 days [16]. Common colds brought a large economic loss on societies at school and at work [17].

After that, the cross-sectional European Common Colds study (COCO) was investigated, in which 2204 patients from 22 European primary care sites in 12 countries were studied for the self-care behavior. They included high self-care use, such as discomfort, female gender, chronic pain, more years of education, $<48$ years and lack of knowledge [18].

Symptoms of common cold are the most frequent reason for selfcare, but the characteristic self-care targets predominantly chronic problem rather than acute self-limited situations [19]. However, recent study revealed that health-related quality of life (HRQOL) was significantly higher in the patients having colds with self-medication first than those visited physician immediately [20]. There was a research

*Correspondence to: Hiroshi Bando, Tokushima University, Medical Research, Nakashowa 1-61, Tokushima 770-0943 Japan, Tel: +81-90-3187-2485; E-mail: pianomed@bronze.ocn.ne.jp

Key words: common cold, Primary Care (PC), Self-Perceived Respiratory Symptoms (SRS), New Elderly Association (NEA), Hinohara-ism

Received: October 09, 2018; Accepted: October 19, 2018; Published: October 22,2018 
of patients with self-diagnosed common cold symptoms using an anonymous self-report questionnaire [21]. Lots of them visited medical institutions because they felt reassured and felt that their symptoms were relieved at a quicker speed. From these, there will be necessary for accurate information and relief from anxiety as to the management of the common cold.

People need appropriate self-care for their own health care. They can understand their physical and mental condition, if they have high degree of health literacy [22]. Furthermore, they can work and lead a satisfactory life with it. These are not passive knowledge of health education, but voluntarily continuous practice of healthy life.

It was Dr. Shigeaki Hinohara of St. Luke's International Hospital that introduced primary care medicine from United States to Japan [23]. He developed primary care over decades and is called "the father of primary care in Japan". He has founded the "New Elderly Association (NEA)", taught how to manage health for many people and enlightened the philosophy of Hinohara-ism broadly [24]. Therefore, health care and self-care in Japan have developed and seemed to be in rather high degree. These useful health management mentioned in this article would be beneficial to people in the medical practice and health education in the future.

\section{References}

1. American Medical Association (1966) The Graduate Education of Physicians; The Report of the Citizen's Commission of Graduate Medical Education (Millis Commission). Chicago 179

2. Doohan NC, Endres J, Koehn N, Miller J, Scherger JE, et al. (2014) Back to the future: reflections on the history of the future of family medicine. J Am Board Fam Med 27: 839-845. [Crossref]

3. Tokuda Y, Ohde S, Takahashi O, Shakudo M, Yanai H, et al. (2008) Prospective Health Diary Study for New Onset Chest Symptoms in the Japanese General Population. Intern Med 47: 25-31.[Crossref]

4. Cullinan P (1992) Persistent cough and sputum: prevalence and clinical characteristics in south east England. Respir Med 86: 143-149. [Crossref]

5. Richards H, McConnachie A, Morrison C, Murray K, Watt G (2000) Social and gender variation in the prevalence, presentation and general practitioner provisional diagnosis of chest pain. J Epidemiol Community Health 54: 714-718.

6. Eslick GD, Jones MP, Talley NJ (2003) Non-cardiac chest pain: prevalence, risk factors, impact and consulting--a population-based study. Aliment Pharmacol Ther 17: 1115-1124. [Crossref]

7. Linehan MF, Hazell ML, Frank TL, Frank PI (2005) Prevalence of respiratory symptoms in under 5s: 1993 to 2001. Arch Dis Child 90: 516-519. [Crossref]

8. Frank PI, Wicks PD, Hazell ML, Linehan MF, Hirsch S, et al. (2005) Temporal change in the prevalence of respiratory symptoms and obstructive airways disease 19932001. Br J Gen Pract 55: 596-602. [Crossref]
9. Fujimura M, Abo M, Ogawa H, Nishi K, Kibe Y, et al. (2005) Importance of atopic cough, cough variant asthma and sinobronchial syndrome as causes of chronic cough in the Hokuriku area of Japan. Respirology 10: 201-207. [Crossref]

10. Fukuda Y, Nakamura K, Takano T (2005) Accumulation of health risk behaviours is associated with lower socioeconomic status and women's urban residence: a multilevel analysis in Japan. BMC Public Health 5: 53. [Crossref]

11. Richards H, McConnachie A, Morrison C, Murray K, Watt G (2000) Social and gender variation in the prevalence, presentation and general practitioner provisional diagnosis of chest pain. J Epidemiol Community Health 54: 714-718.

12. Saul LJ (1938) Psychogenic Factors in the Etiology of the Common Cold and Related Symptoms. Int J Psycho-Analysis 19: 451.

13. Cohen S, Tyrrell DA, Smith AP (1991) Psychological stress and susceptibility to the common cold. $N$ Engl J Med 325: 606-612. [Crossref]

14. Selinheimo S, Vasankari T, Jokela M, Kanervisto M, Pirkola S (2018) The association of psychological factors and healthcare use with the discrepancy between subjective and objective respiratory-health complaints in the general population. Psychol Med 20: 1-11. [Crossref]

15. Thielmann A, Gerasimovska-Kitanovska B, Koskela TH, Mevsim V, Weltermann B, et al. (2018) Self-care for common colds: A European multicenter survey on the role of subjective discomfort and knowledge about the self-limited course - The COCO study. PLOS ONE 13: e0195564. [Crossref]

16. Blaiss MS, Dicpinigaitis PV, Eccles R, Wingertzahn MA (2015) Consumer attitudes on cough and cold: US (ACHOO) survey results. Curr Med Res Opin 31: 1527-1538. [Crossref]

17. Nichol KL, D'Heilly S, Ehlinger E (2006) Burden of upper respiratory illnesses among college and university students: 2002-2003 and 2003-2004 cohorts. Vaccine 24: 67246725. [Crossref]

18. Weltermann BM, Gerasimovska-Kitanovska B, Thielmann A, Chambe J, Lingner H, et al. (2015) Self-Care Practices for Common Colds by Primary Care Patients: Study Protocol of a European Multicenter SurveyĐThe COCO Study. Evid Based Complement Alternat Med 272189. [Crossref]

19. Parisius LM, Stock-Schröer B, Berger S, Hermann K, Joos S (2014) Use of home remedies: a cross-sectional survey of patients in Germany. BMC Fam Pract 15: 116. [Crossref]

20. Shaku F, Tsutsumi M, Miyazawa A, Takagi H, Maeno T (2015) Self-care behavior when suffering from the common cold and health-related quality of life in individuals attending an annual checkup in Japan: A cross-sectional study. BMC Fam Pract 16: 137. [Crossref]

21. Madoka Tsutsumi, Fumio Shaku, Sachiko Ozone, Naoto Sakamoto, Tetsuhiro Maeno (2017) Reasons for the preference of clinic visits to self-medication by common cold patients in Japan. J Gen Fam Med 18: 336-340. [Crossref]

22. Hersh L, Salzman B, Snyderman D (2015) Health Literacy in Primary Care Practice. Am Fam Physician 92: 118-124. [Crossref]

23. Bando H, Yoshioka A, Iwashimizu Y, Iwashita M, Doba N (2017) Development of Primary Care, Lifestyle Disease and New Elderly Association (NEA) in Japan Common Philosophy with Hinohara-ism. Prim Health Care 7: 281.

24. Hinohara S (2007) Preparations to Stay Hale and Hearty in Your Old Age. J Jap Assoc Rural Med 55: 553-564.

Copyright: (C2018 Bando H. This is an open-access article distributed under the terms of the Creative Commons Attribution License, which permits unrestricted use, distribution, and reproduction in any medium, provided the original author and source are credited. 